OPEN ACCESS

Edited by:

Maria Pia Amato,

University of Florence, Italy

Reviewed by:

Brian M. Sandroff,

Kessler Foundation, United States

Mattia Fonderico,

Università di Firenze, Italy

*Correspondence:

Andrius Kavaliunas

andrius.kavaliunas@gmail.com

Specialty section:

This article was submitted to

Multiple Sclerosis and

Neuroimmunology,

a section of the journal

Frontiers in Neurology

Received: 06 July 2021 Accepted: 25 November 2021

Published: 06 January 2022

Citation:

Kavaliunas A, Danylaite

Karrenbauer V, Binzer S and Hillert J (2022) Systematic Review of the

Socioeconomic Consequences in

Patients With Multiple Sclerosis With Different Levels of Disability and

Cognitive Function.

Front. Neurol. 12:737211

doi: 10.3389/fneur.2021.737211

\section{Systematic Review of the Socioeconomic Consequences in Patients With Multiple Sclerosis With Different Levels of Disability and Cognitive Function}

\author{
Andrius Kavaliunas ${ }^{1 *}$, Virginija Danylaite Karrenbauer ${ }^{1,2}$, Stefanie Binzer ${ }^{1,3}$ and \\ Jan Hillert ${ }^{1,2}$
}

${ }^{1}$ Department of Clinical Neuroscience, Karolinska Institutet, Stockholm, Sweden, ${ }^{2}$ Neurology Medical Unit, Karolinska University Hospital, Huddinge, Sweden, ${ }^{3}$ Department of Neurology, Kolding Hospital, Kolding, Denmark

Multiple sclerosis (MS) is a challenging and disabling condition, predominantly affecting individuals in early adulthood. MS affects the physical, cognitive, and mental health of persons suffering from the disease as well as having a great impact on their financial status and quality of life. However, there is a lack of systematic approach toward assessing the socioeconomic consequences of MS. Our objective was to systematically review analytical observational studies investigating the socioeconomic consequences in persons with MS with different levels of physical disability and cognitive function. We conducted a systematic review on socioeconomic consequences of MS with a focus on employment-, income-, work ability-, and relationship-related outcomes in persons with MS with special focus on disability and cognition. Additionally, the educational characteristics were examined. From 4,957 studies identified, 214 were assessed for eligibility and a total of 19 studies were included in this qualitative assessment; 21 different outcomes were identified. All identified studies reported higher unemployment, higher early retirement, and higher risk of unemployment in relation to higher physical disability. Also, cognitive function was found to be a predictor of employment (unemployment). The studies pointed out significant correlations between greater disability and lower earnings and higher income from benefits. A study found the same correlation in relation to cognitive function. The studies reported higher work disability in relation to higher physical disability and lower cognitive function. In conclusion, this systematic review summarizes the pronounced differences in various socioeconomic outcomes between patients with MS with regards to their physical disability and cognitive function. In addition, we identified a lack of studies with longitudinal design in this field that can provide more robust estimates with covariate adjustments, such as disease modifying treatments.

Keywords: multiple sclerosis (MS), employment, socioeconomic factors, income, sick leave, systematic review, disability evaluation, cognition 


\section{INTRODUCTION}

Approximately 2.8 million people worldwide are affected with multiple sclerosis (MS) - a chronic demyelinating and neurodegenerative disease of the central nervous system with increasing prevalence $(1,2)$. MS poses a major personal and socioeconomic burden: the average age of disease onset is 30 years-a time that is decisive for work and family planning; persons with MS die 7-10 years earlier and live on average almost 20 years with moderate and 30 years with severe disability $(1,3,4)$. The condition has a heterogeneous presentation that can include sensory and visual disturbances, motor function impairments, fatigue, pain, and cognitive deficits $(1,5)$.

Within the MS population, the spectrum of disability ranges from essentially unaffected to highly disabled. The most common measure utilized to assess physical disability is the Expanded Disability Status Scale (EDSS) (6), which is based on a standardized neurological examination in combination with assessment of walking distance, arm function, speech, and utilization of walking aid and wheelchair; however, it is nonlinear and some functional score items are evaluated subjectively. As the disability of patients increases, they become dependent on their family for carrying out their daily routines and activities, which leads to a reduction of their quality of life (7). Even in a population with low physical disability, MS is responsible for a substantial economic burden due to indirect and informal care costs (8). In addition, we previously reported that the average level of earnings was ten times lower and the average level of health-related benefits was four times higher when comparing patients with MS with severe and mild disability (9).

Cognitive decline is recognized as a prevalent and debilitating symptom of multiple sclerosis (10). Measurable cognitive dysfunction has been reported in up to $70 \%$ of patients (11). Various aspects of cognitive function can be detrimentally affected: difficulties with long-term and verbal memory, abstract and conceptual reasoning, fluency, planning, visuospatial perception, and reduced speed of information processing (11). In addition, the cognitive function affects the financial situation of persons with MS negatively, independently of physical disability, e.g., persons with MS in the highest Symbol Digit Modalities Test (SDMT) quartile earned more than two times annually compared with those in the lowest SDMT quartile (12).

Previously, we summarized the pronounced differences between patients with MS and the general population, e.g., 15-30\% lower employment, lower earnings and higher social benefits, higher absenteeism and presenteeism proportions, and higher work disability (e.g., sick leave days) among persons with MS (13). However, besides underlying differences between MS and general population, persons with MS are quite different in terms of progression of physical disability, reduction of cognitive function, etc. As socioeconomic outcomes can be investigated

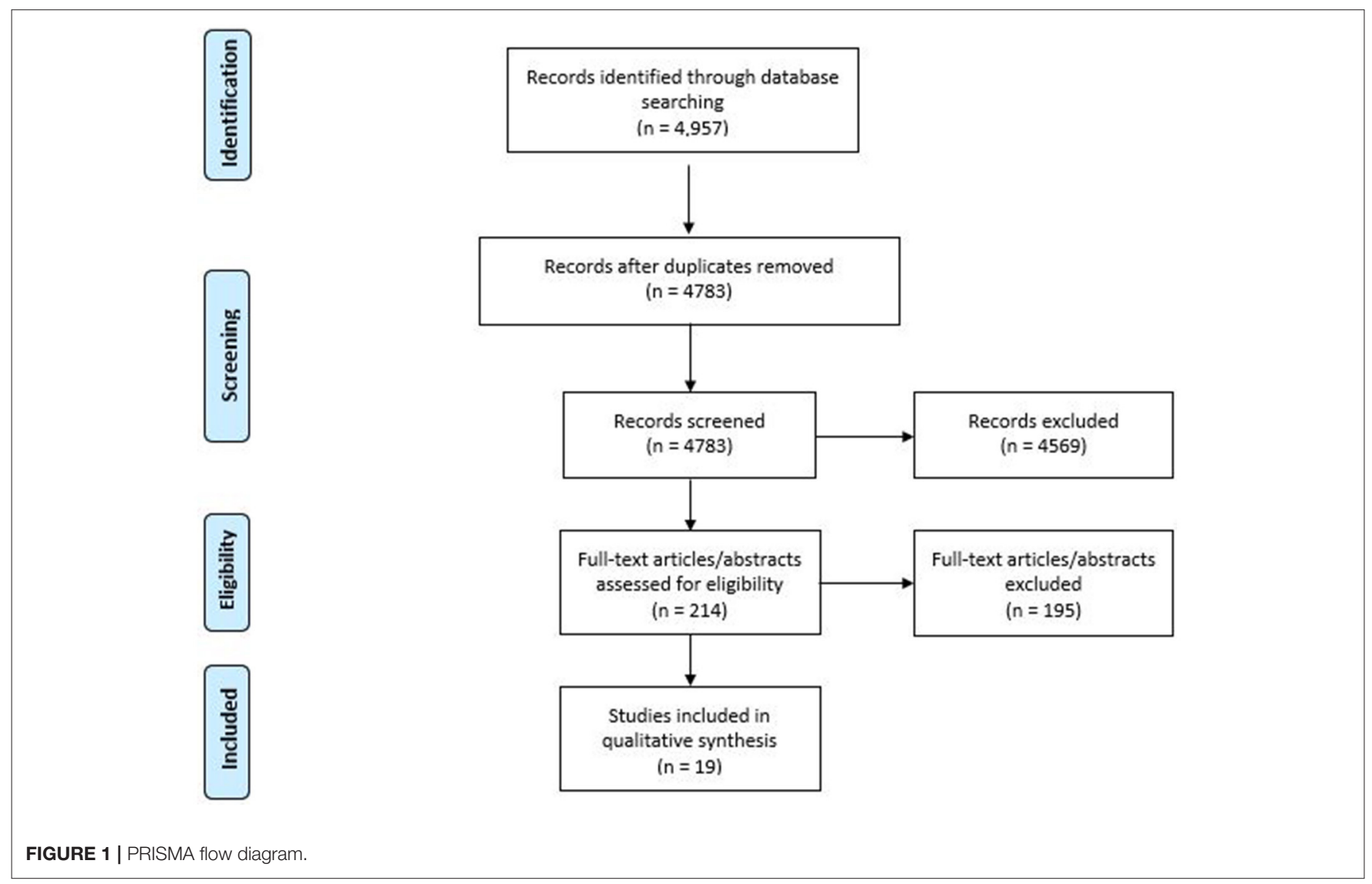


in many ways (e.g., income, employment, marital status, sick leave days, etc.) a comprehensive overview is warranted. Thus, our aim was to systematically review the studies investigating the socioeconomic consequences in persons with MS in regard to their physical disability and cognition.

\section{METHODS}

We conducted a systematic review following the Preferred Reporting Items for Systematic Reviews and MetaAnalyses (PRISMA) statement (14). The study protocol was registered in PROSPERO: International prospective register of systematic reviews (https://www.crd.york.ac.uk/ prospero/), ID: CRD42020182085. Published studies on socioeconomic consequences of MS were systematically searched in Medline (Ovid), Embase, and Web of Science (Clarivate). A combination of relevant keywords to construct the search strategy, such as MS, socioeconomic outcomes, employment, income, earnings, benefits, disability pension, sickness absence, sick leave, and marital status, was used (full search strategy is available in Supplementary Material 1). The search was limited to English language and publications prior to July 2019.

One author (AK) conducted the first screening of potentially relevant records based on titles and abstracts, and two authors (AK and VDK) independently performed the final selection of included studies based on full text evaluation against the eligibility criteria. Rayyan, a web and mobile app for systematic reviews (https://rayyan.qcri.org/welcome) was used to facilitate the review process. Consensus between the two reviewers was used to resolve any disagreement.

The main eligibility criteria were:

- Population: adults of working age;

- Exposures: higher physical disability level assessed by EDSS (6); lower cognitive function assessed by SDMT (15);

- Comparators: lower physical disability level assessed by EDSS (6); higher cognitive function assessed by SDMT (15);

- Outcomes: socioeconomic outcomes (employment, income, work ability, education, and relationship);

- Study design: analytical observational studies (e.g., cohort, case-control, and cross-sectional) (16), excluding descriptive studies, case reports, and case series. Clinical trials and economic evaluations (e.g., cost if illness and cost-effectiveness studies) were not in the scope of this review.

Initially 4,957 studies were identified (Figure 1) and 4,783 records were screened after duplicates were removed. In total, 214 full-text articles (or abstracts) were assessed for eligibility and finally 19 studies were included in the qualitative synthesis. Only full articles were considered for the qualitative analysis. Studies that did not report any estimates (e.g., proportions and ratios), only pointing out to the direction (higher, lower) or association (e.g., significant and not significant) were not considered for the evaluation. Using a standardized data extraction form in Excel, study characteristics (as presented in the tables and Supplementary Material 2) were extracted from the included
TABLE 1 | The list of socioeconomic outcomes.

Outcomes References

Employment-related outcomes:

Proportion of the employed (fully or partially) or unemployed;

Proportion of early retirement;

$(17-25)$

$(19,22,24)$

Odds ratio (OR) for employment (unemployment).

$(18,20,23,26-28)$

Income-related outcomes:

Mean annual income (earnings, benefits);

Median annual income (earnings, benefits);

$(9,12)$

Proportion receiving earnings (earnings $>0$ );

$(12,18)$

$(9,12)$

Proportion receiving social benefits;

$(9,12,19,24)$

Percental difference in income;

(9)

OR for having income (earnings, benefits);

$(9,12)$

Prevalence ratio for having income (earnings, benefits);

$(9,12)$

Adjusted regression coefficient for amount of income

$(9,12)$

(earnings, benefits).

\section{Work ability-related outcomes:}

OR for full and/or partial sick leave;

Proportion on full-time disability pension;

(30)

Absenteeism (correlation coefficient, regression

coefficient);

Presenteeism (correlation coefficient, regression

coefficient);

Proportion on absence at work;

Work disability (annual net days of sickness absence and disability pension);

Incidence rate ratio (IRR) for work disability;

Predicted marginal mean of work disability.

Relationship outcomes:

Proportion of a relationship status (e.g. married/cohabitant, single).

\section{Educational level:}

Proportion of those having school/high-school/university education.

\section{(31)}

(31)

(32)

(33)

(33)

(33)

$(9,33)$

$(9,12,33)$

studies. In case of possible overlap in a study population, the most recent study was selected.

Three reviewers (AK, VDK, and SB; two per each study) independently assessed the quality of the included studies focusing on such study characteristics as study design (cohort studies prioritized over cross-sectional), data sources (registries and databases prioritized over surveys and interviews), timeline, and the size of the study population. Accordingly, on the basis of the aforementioned study characteristics, each study was evaluated by points, whereby this is reflected in the final grading (A-high quality; $\mathrm{B}$-moderate quality; $\mathrm{C}$-low quality). Consensus was used to resolve any disagreement. The quality assessment was performed ensuring that at least one of the reviewers is not among the co-authors (Supplementary Material 2).

Our aim was to broadly review the studies with regards to the socioeconomic outcomes analyzed, thus we applied a comprehensive search strategy to include all possible 
TABLE 2 | Studies that investigated employment-related outcomes in patients with multiple sclerosis (MS) within different levels of physical disability.

\begin{tabular}{|c|c|c|c|c|c|}
\hline First author & Country & Population (n) & \multicolumn{3}{|c|}{ Main results } \\
\hline & & & Working full-time & 0-3: $\mathbf{3 . 0 \%}$ & 4-6.5: 7\%; 7-9: $\mathbf{3 . 8 \%}$ \\
\hline & & & Early retired & $0-3: \mathbf{0 . 6 \%}$ & 4-6.5: $\mathbf{5 . 5 \% ; ~ 7 - 9 : ~} \mathbf{1 4 . 8 \%}$ \\
\hline \multirow[t]{2}{*}{ Boe Lunde et al. (20) } & Norway & 213 & Employed & $0-3: \mathbf{7 0 . 8 \%}$ & 3.5-6: $\mathbf{3 9 . 6 \% ; ~ > 6 : ~} \mathbf{6 . 1 \%}$ \\
\hline & & & $\begin{array}{l}\text { Adjusted OR (95\% Cl) for } \\
\text { unemployment }\end{array}$ & 0-3: 1 & $\begin{array}{l}3.5-6: 0.34(0.15-0.77) \\
>6: 0.05(0.01-0.26)\end{array}$ \\
\hline Busche et al. (21) & Canada & 96 & Employed & $0-2.5: 60.0 \%$ & $\begin{array}{c}3-5.5: \mathbf{2 8} \% ; \text {; 6-8: } \mathbf{1 2 \%} ; \\
8.5-9.5 \%: 0 \%\end{array}$ \\
\hline Findling et al. (22) & Switzerland & 405 & Full-time working & 0-2.5: $\mathbf{4 1 . 4 \%}$ & 3-4.5: $21.5 \% ;>5: 4.9 \%$ \\
\hline \multirow[t]{2}{*}{ Koziarska et al. (26) } & Poland & 150 & OR (95\% Cl) for unemployment & 0-3: 1 & $>3: \mathbf{1 3 . 2 2 7}(5.221-38.741)$ \\
\hline & & & $\begin{array}{l}\text { Adjusted OR (95\% Cl) for } \\
\text { unemployment }\end{array}$ & 0-3: 1 & $>3: \mathbf{1 1 . 0 8 9}(4.116-34.201)$ \\
\hline \multirow[t]{2}{*}{ Lau et al. (23) } & Hong Kong & 59 & Employed & $\leq 5.5: 97 \%$ & $>5.5: \mathbf{3} \%$ \\
\hline & & & OR (95\% Cl) for employment & $\leq 5.5: 1$ & $>5.5: 0.071(0.003-1.775)$ \\
\hline \multirow[t]{2}{*}{ MacLurg et al. (24) } & UK & 149 & Employed & $0-4.5: 43 \%$ & $5-6.5: \mathbf{2 1} \% ; 7-9.5: \mathbf{8} \%$ \\
\hline & & & Medically retired & 0-4.5: $\mathbf{3 4 \%}$ & 5-6.5: 51\%; 7-9.5: 75\% \\
\hline Pearson et al. (18) & New Zealand & 1727 & Proportion not working & $<3: 30.5 \%$ & $\begin{array}{l}3-6: \mathbf{5 0 . 6 \%} \\
>6: \mathbf{8 4 . 8 \%}\end{array}$ \\
\hline
\end{tabular}

EDSS, Expanded Disability Status Scale; OR, odds ratio.

“Austria, Belgium, Czech Republic, Denmark, France, Germany, Hungary, Italy, the Netherlands, Poland, Portugal, Russia, Spain, Sweden, Switzerland, the United Kingdom. Bold values shows the estimate.

operationalized definitions. In total, 21 different outcomes were identified. We grouped the outcomes into the categories of employment-, income-, work ability-, and relationship-related outcomes, also mapping the reported indicators for each of the included study (Table 1). Additionally, we extracted the information about the educational level from the selected studies. The employment domain consisted of such keywords as employment, unemployment, work, labor, occupational status; income domain-income, salary, earnings, benefits, compensation, remuneration; the work ability domainwork ability, work disability, sick leave, sickness absence, disability pension, absenteeism, presenteeism; relationship domain: marital status, relationship status, divorce, etc. (Supplementary Material 1). Results from the studies were qualitatively compared and summarized. We used the original categorization of EDSS and SDMT values, as it was reported in the studies. As many authors use different categories, we classified the lowest reported EDSS category into "lower EDSS" and the remaining into "higher EDSS," similarly for SDMT.

\section{RESULTS}

A total of 19 studies were selected for inclusion into this systematic review of socioeconomic consequences of MS in relation to physical disability and cognitive function. Of them, 18 studies provided data from their respective countries, and one study was multi-center with the results from 16 European countries. The majority of studies (12 of 17) were conducted in Europe (with half of them in the Scandinavian countries, i.e., five in Sweden and one in Norway); four studies-in North America (three in USA and one in Canada); one-study in Hong Kong and one in New Zealand.

With respect to study design, three were cohort studies and 16-cross-sectional studies; four studies analyzed data from 
TABLE 3 | Studies that investigated employment-related outcomes in patients with MS within different levels of cognitive function.

\begin{tabular}{|c|c|c|c|c|c|}
\hline \multirow[t]{2}{*}{ First author } & \multirow[t]{2}{*}{ Country } & \multirow[t]{2}{*}{ Population } & \multicolumn{3}{|c|}{ Main results } \\
\hline & & & Outcomes & Higher SDMT & Lower SDMT \\
\hline Campbell et al. (25) & UK & 62 & Employment rate & $\begin{array}{l}\text { 60-80: } 100 \% \\
\text { 50-60: } \sim 60 \%\end{array}$ & $\begin{array}{l}\text { 40-50: } \sim \mathbf{4 5 \%} \\
\text { 30-40: } \sim 20 \% \\
\text { 20-30: } \sim 0 \%\end{array}$ \\
\hline Fraser et al. (28) & US & 95 & $\begin{array}{l}\text { OR for fully employed vs. } \\
\text { unemployed for a } 1 \mathrm{SD} \\
\text { difference in measure }\end{array}$ & \multicolumn{2}{|c|}{$\begin{array}{l}\text { SDMT written - } 1.76(0.89-3.53) \\
\text { SDMT oral - } 1.46(0.75-2.83)\end{array}$} \\
\hline Morrow et al. (27) & US & 97 & \multicolumn{3}{|c|}{$\begin{array}{l}\text { Adjusted OR was } 4.2(95 \% \mathrm{Cl}, 1.2-14.8) \text { of a deterioration in employment (paid disability } \\
\text { benefits or a reduction in working hours) based on a change of SDMT by } 4.0\end{array}$} \\
\hline
\end{tabular}

Cl, confidence intervals; OR, odds ratio; SDMT, Symbol Digit Modalities Test. Bold values shows the estimate.

the registries, whereas 14 studies included data from surveys, questionnaires, or interviews (note, one study did not provided information about the data source used). The selected studies are summarized in the Tables 2-9 and categorized according to the functional domain (physical disability or cognitive function), and type of outcome.

\section{Employment-Related Outcomes}

We identified 12 studies that investigated the employmentrelated outcomes: nine in relation to physical disability (Table 2) and three in relation to cognitive function (Table 3 ). The largest study conducted in 16 European countries, which included 16,808 patients with MS, found gradually decreasing workforce participation (proportion of the patients below retirement age employed or self-employed) in relation to physical disability from $82 \%$ at EDSS 0 to $8 \%$ at EDSS 9 (17). Similarly, a study in New Zealand (18) that surveyed 1,727 patients with MS showed much higher proportion of persons not working with increasing EDSS levels: $84.8 \%$ among those with EDSS >6, 50.6\% among those with EDSS 3-6, and 30.5\% among those with EDSS $<3$. Correspondingly, a study in Italy (19) that included 1,010 patients with MS reported similar findings: the proportion of employed patients with MS was $16 \%$ at EDSS $7-9,45.4 \%$ at EDSS $4-6.5$, and $68.6 \%$ at EDSS $0-3$. Other smaller studies in Norway (20), Canada (21), Switzerland (22), Hong Kong (23), and the United Kingdom (24) presented similar results.

In addition, three studies explored early retirement due to disease (medical retirement, and invalidity) pointing to a higher proportion among those with higher physical disability level, e.g., $75 \%$ among those with EDSS 7-9.5 in the United Kingdom (24), and $69.2 \%$ among those with EDSS $>5$ in Switzerland, (22) but $14.8 \%$ among those with EDSS 7-9 in Italy (19).

Four studies investigated and reported odds ratios (ORs) for employment/unemployment. With regards to unemployment, in New Zealand adjusted $O R$ for unemployment was 2.05 (95\% CI, 1.59-2.64) for those with EDSS 3-6, and 9.32 (95\% CI, 6.66-13.19) for those with EDSS > 6, when compared with those with EDSS $<3$ (18). This was more pronounced in Poland with adjusted $O R$ for unemployment of 11.089 (95\% CI, 4.116-34.201) for those with EDSS >3 (26).
Correspondingly, with regards to employment, a Norwegian study found that adjusted $O R$ for employment was 0.05 (95\% $C I, 0.01-0.26)$ for those with EDSS $>6$ when compared with those with EDSS 0-3; and $O R$ for employment in Hong Kong was 0.071 (95\% CI, 0.003-1.775) for those with EDSS $>5.5$ (23).

To sum up, all identified studies reported higher unemployment, higher early retirement, and higher odds for unemployment in relation to higher physical disability.

Additionally, we identified three studies investigating the employment-related outcomes within different levels of cognitive function. A study in the United Kingdom (25) reported higher employment rate in relation to higher SDMT scores, e.g., $100 \%$ with SDMT 60-80, 60\% with SDMT 50-60, 45\% with SDMT 40-50, 20\% with SDMT 30-40, and $0 \%$ with SDMT 20-30, concluding that SDMT was the most significant predictor of unemployment. Similarly, two studies in the United States explored odds for unemployment associated with changes in SDMT: Morrow et al. (27) concluded that decline on neuropsychological tests, such as SDMT, over time is predictive of deterioration in vocational status, and Fraser et al. (28), summarizing that relatively brief, simple tests (such as SDMT) appear to be very tangible predictors of one's ability to both secure and retain employment.

\section{Income-Related Outcomes}

In total, five cross-sectional studies investigated incomerelated outcomes; four of them with regards to physical disability (Table 4), and one-with regards to cognitive function (Table 5). The largest study in Sweden (9) that included 7,929 patients with MS comprehensively described income of persons with MS in relation to physical disability level, and found significant correlations between greater disability and lower earnings and higher income from benefits: individuals with severe disability had 59\% lower earnings and 92\% higher benefits than patients with mild disability. In addition, the proportion of patients receiving some type of benefits was two times as high in the group with severe disabilitywhere almost everyone received benefits-compared with the group of patients with mild disability. The patients with 
TABLE 4 | Studies that investigated income-related outcomes in patients with MS within different levels of physical disability.

\begin{tabular}{|c|c|c|c|c|c|}
\hline \multirow[t]{2}{*}{ First author } & \multirow[t]{2}{*}{ Country } & \multirow{2}{*}{$\begin{array}{l}\text { Population } \\
\text { (n) }\end{array}$} & \multicolumn{3}{|c|}{ Main results } \\
\hline & & & Outcomes & Lower EDSS & Higher EDSS \\
\hline Battaglia et al. (19) & Italy & 1010 & Invalidity pension & 0-3: $\mathbf{1 . 7 \%}$ & 4-6.5: $\mathbf{1 9 . 2 \% ; ~ 7 - 9 : ~} \mathbf{3 9 . 1 \%}$ \\
\hline \multirow[t]{12}{*}{ Kavaliunas et al. (9) } & Sweden & 7929 & Earnings $>0$ & 0-3.5: $84.7 \%$ & $\begin{array}{l}4-5.5: \mathbf{5 7 . 9 \%} ; 6-6.5: \\
\mathbf{4 4 . 0 \% ;} 7-9.5: \mathbf{2 1 . 0} \%\end{array}$ \\
\hline & & & Earnings, mean in SEK 100 & 0-3.5: 2140.9 & $\begin{array}{l}\text { 4-5.5: 1154.5; 6-6.5: } \\
\text { 763.6; 7-9.5: } 218.7\end{array}$ \\
\hline & & & Health related benefits, mean in SEK 100 & $0-3.5: 349.5$ & $\begin{array}{l}\text { 4-5.5: 932.1; 6-6.5: } \\
\mathbf{1 2 3 2 . 2} ; 7-9.5: \mathbf{1 4 1 9 . 8}\end{array}$ \\
\hline & & & Disability pension & 241.3 & 720.3; 1019.6; 1239.4 \\
\hline & & & Sickness absence & 102.9 & 177.2; 136.3; 53.7 \\
\hline & & & Unemployment compensation & 29.5 & $14.6 ; 4.2 ; 3.1$ \\
\hline & & & Social assistance & 6.6 & $8.1 ; 4.7 ; 12.1$ \\
\hline & & & Percentage change in earnings & 0-3.5: reference & $\begin{array}{c}4-5.5:-\mathbf{2 1 . 1} \% ; 6-6.5: \\
-\mathbf{3 1 . 3} \% ; 7-9.5:-\mathbf{5 8 . 8} \%\end{array}$ \\
\hline & & & Percentage change in benefits & 0-3.5: reference & $\begin{array}{c}\text { 4-5.5: +49.3\%; 6-6.5: } \\
+\mathbf{7 3 . 0 \%} ; 7-9.5:+92.0 \%\end{array}$ \\
\hline & & & Adjusted OR (95\% Cl) for having earnings* & 0-3.5: 1 & $\begin{array}{l}4-5.5: 0.32(0.27-0.37) \\
6-6.5: 0.21(0.17-0.24) \\
7-9.5: 0.07(0.06-0.09)\end{array}$ \\
\hline & & & Adjusted OR (95\% Cl) for having benefits* & 0-3.5: 1 & $\begin{array}{c}4-5.5: 4.06(3.33-4.96) ; \\
6-6.5: \mathbf{1 2 . 7 2}(9.09-17.80) ; \\
7-9.5: 89.13 \\
(36.73-216.28)\end{array}$ \\
\hline & & & $\begin{array}{l}\text { Adjusted regression ( } 95 \% \text { Cl) coefficient for } \\
\text { level of benefits }\end{array}$ & 0-3.5: reference & $\begin{array}{c}4-5.5: \mathbf{2 8 5 . 5 0} \\
(244.92-326.08) ; 6-6.5: \\
\mathbf{4 2 2 . 7 4}(381.30-464.18) \\
7-9.5: \mathbf{5 4 5 . 3 4} \\
(501.90-588.78)\end{array}$ \\
\hline MacLurg et al. (24) & UK & 149 & $\begin{array}{l}\text { Disability related income } \\
\text { Other benefits }\end{array}$ & $\begin{array}{l}0-4.5: 40 \% \\
0-4.5: 6 \%\end{array}$ & $\begin{array}{l}\text { 5-6.5: } \mathbf{8 9} \% ; 7-9.5: \mathbf{9 1} \% \\
\text { 5-6.5: } \mathbf{2 3} \% ; 7-9.5: \mathbf{1 5} \%\end{array}$ \\
\hline Pearson et al. (18) & New Zealand & 1727 & Median income (NZD) & $<3: \mathbf{3 0 . 0 0 0}$ & $3-6: \mathbf{2 0 . 0 0 0} ;>6: \mathbf{1 5 . 0 0 0}$ \\
\hline
\end{tabular}

EDSS, Expanded Disability Status Scale; OR, odds ratio; $R R$, risk ratio.

${ }^{*}$ Crude ORs are available in the original article but were not extracted to this review. Bold values shows the estimate.

MS with severe disability (EDSS $\geq 7$ ) had on average SEK 166,931 less annual income from earnings and SEK 54,534 more income from benefits ( $\sim$ EUR 17,600 and EUR 5,700, respectively) compared to those with mild disability. Persons with MS with mild and moderate mild disability (EDSS 0-5.5), mostly had earnings, whereas those with moderate severe and severe disability (EDSS 6-9.5) had their main source of income from disability pension. The adjusted risk ratio for 
TABLE 5 | Studies that investigated income-related outcomes in patients with MS within different levels of cognitive function.

\begin{tabular}{|c|c|c|c|c|c|}
\hline First author & Country & Population & \multicolumn{3}{|c|}{ Main results } \\
\hline & & & Earnings mean (SEK 100) & $\begin{array}{l}\text { QIV (62-110): } 2282 \\
\text { QIII (54-61): } 1968\end{array}$ & $\begin{array}{l}\text { QII (45-53): } 1728 \text { QI } \\
\text { (6-44): } 1046\end{array}$ \\
\hline & & & Proportion of benefits $>0$ & $\begin{array}{l}\text { QIV (62-110): } \mathbf{4 8 . 5} \% \\
\text { QIII (54-61): } \mathbf{6 2 . 1 \%}\end{array}$ & $\begin{array}{l}\text { QII (45-53): } \mathbf{6 4 . 5} \% \\
\text { QI (6-44): } \mathbf{8 3 . 5} \%\end{array}$ \\
\hline & & & Benefits mean (SEK 100) & $\begin{array}{l}\text { QIV (62-110): } \mathbf{2 8 7} \\
\text { QIII (54-61): } 495\end{array}$ & $\begin{array}{l}\text { QII (45-53): } 586 \text { QI } \\
\quad(6-44): 898\end{array}$ \\
\hline & & & Benefits median (SEK 100) & $\begin{array}{l}\text { QIV (62-110): } 0 \\
\text { QIII (54-61): } 161\end{array}$ & $\begin{array}{l}\text { QII (45-53): } 393 \mathrm{QI} \\
\quad(6-44): \mathbf{9 6 6}\end{array}$ \\
\hline & & & Adjusted OR $(95 \% \mathrm{Cl})$ for having benefits & $\begin{array}{l}\text { QIV: } \mathbf{0 . 4 1}(0.29-0.59) \\
\text { QIII: } \mathbf{0 . 5 7}(0.40-0.80)\end{array}$ & $\begin{array}{l}\text { QII: } \mathbf{0 . 5 1}(0.36-0.71) \\
\text { QI: } 1\end{array}$ \\
\hline & & & Corrected PR $(95 \% \mathrm{Cl})$ for having benefits & $\begin{array}{l}\text { QIV: } \mathbf{0 . 8 1}(0.71-0.90) \\
\text { QIII: } \mathbf{0 . 8 9}(0.80-0.96)\end{array}$ & $\begin{array}{l}\text { QII: } \mathbf{0 . 8 6}(0.78-0.94) \\
\text { Ql: } 1\end{array}$ \\
\hline & & & $\begin{array}{l}\text { Adjusted coefficient (95\% Cl) for amount of earnings } \\
\text { (estimate in SEK 100) }\end{array}$ & $\begin{array}{l}\text { QIV: } 722(504-941) \\
\text { QIII: } 497(288-707)\end{array}$ & $\begin{array}{l}\text { Qll: } 403 \text { (200-606) } \\
\text { QI: Reference }\end{array}$ \\
\hline & & & $\begin{array}{l}\text { Adjusted coefficient (95\% Cl) for amount of benefits } \\
\text { (estimate in SEK 100) }\end{array}$ & $\begin{array}{c}\text { QIV: -210 } \\
(-296--123) \\
\text { QIII: -93 } \\
(-170--53)\end{array}$ & $\begin{array}{l}\text { Qll: } \mathbf{- 5 8}(-128-13) \\
\quad \text { Ql: Reference }\end{array}$ \\
\hline
\end{tabular}

OR, odds ratio; PR, prevalence ratio; Q, quartile; SDMT, Symbol Digit Modalities Test. Bold values shows the estimate.

having earnings among persons with MS with severe disability compared with the persons with mild disability was 0.33 (95\% CI, 0.29-0.39), while the risk ratio for receiving benefits was 1.93 (95\% CI, 1.90-1.94).

Similarly, the other two studies reported an increasing proportion of persons with MS on benefits with increasing physical disability: from $40 \%$ receiving disability related income at EDSS $0-4.5$ to $91 \%$ at EDSS 7-9.5 in the United Kingdom (24) and from $1.7 \%$ receiving invalidity pension at EDSS $0-3$ to $39.1 \%$ at EDSS 7-9 in Italy (19). In New Zealand, the median annual income for those with greater disability was two times lower $($ NZD 15,000 at EDSS $>6$ and NZD 30,000 at EDSS <3) (18).

To summarize, the studies pointed out significant correlations between greater disability and lower earnings and higher income from benefits.

With regards to the cognitive function and income among persons with MS, a Swedish study (12) thoroughly explored this, assessed with SDMT: persons in the highest SDMT score quartile earned more than two times annually compared with those in the lowest quartile, whereas persons in the lowest quartile received three times more income through social benefits. The difference in earnings and benefits across the SDMT performance quartiles remained statistically significant after adjusting for various clinical and socio-demographic variables, such as physical disability. The corrected prevalence ratios for persons with MS in the highest quartile having income from earnings and benefits were 1.40 (95\% CI, 1.29-1.49) and 0.81 (95\% CI, 0.71-0.90), respectively, when compared with the persons in the lowest quartile.

\section{Work Ability-Related Outcomes}

We identified five studies that investigated work ability-related outcomes, two of them were cohort and three were crosssectional in study design. Two studies explored work ability in relation to disability (Table 6) $(29,32)$, one-in relation to cognitive function (Table 7) (30), and two in relation to both disability and cognition (Tables 6, 7) $(31,33)$. Two Swedish studies assessed the risk for work ability: Kavaliunas et al. (33) reported increasing adjusted incidence rate ratios (IRRs) with higher disability both at 1- and 3-year follow-ups: 2.42 (95\% CI, 1.72-3.39) and 2.61 (95\% CI, 1.72-3.39), respectively, at EDSS 7.9-5 when compared with those with EDSS 0-3.5. Whereas, Sundstrom et al. (29) reported both increasing odds for full sick leave and partial or full sick leave with greater disability: 34 (95\% CI, 13-86) and 150 (95\% CI, 19-1,200), respectively, at EDSS $>6$ when compared with those with EDSS 0-3.5. Another study in the United States (31) investigated disability in relation to absenteeism (missing work because of health problems) and presenteeism (impairment while working) and concluded that statistically significant correlations $(0.21-0.43)$ were found between presenteeism (but not absenteeism) and increasing disability. 
TABLE 6 | Studies that investigated work ability-related outcomes in patients with MS within different levels of physical disability.

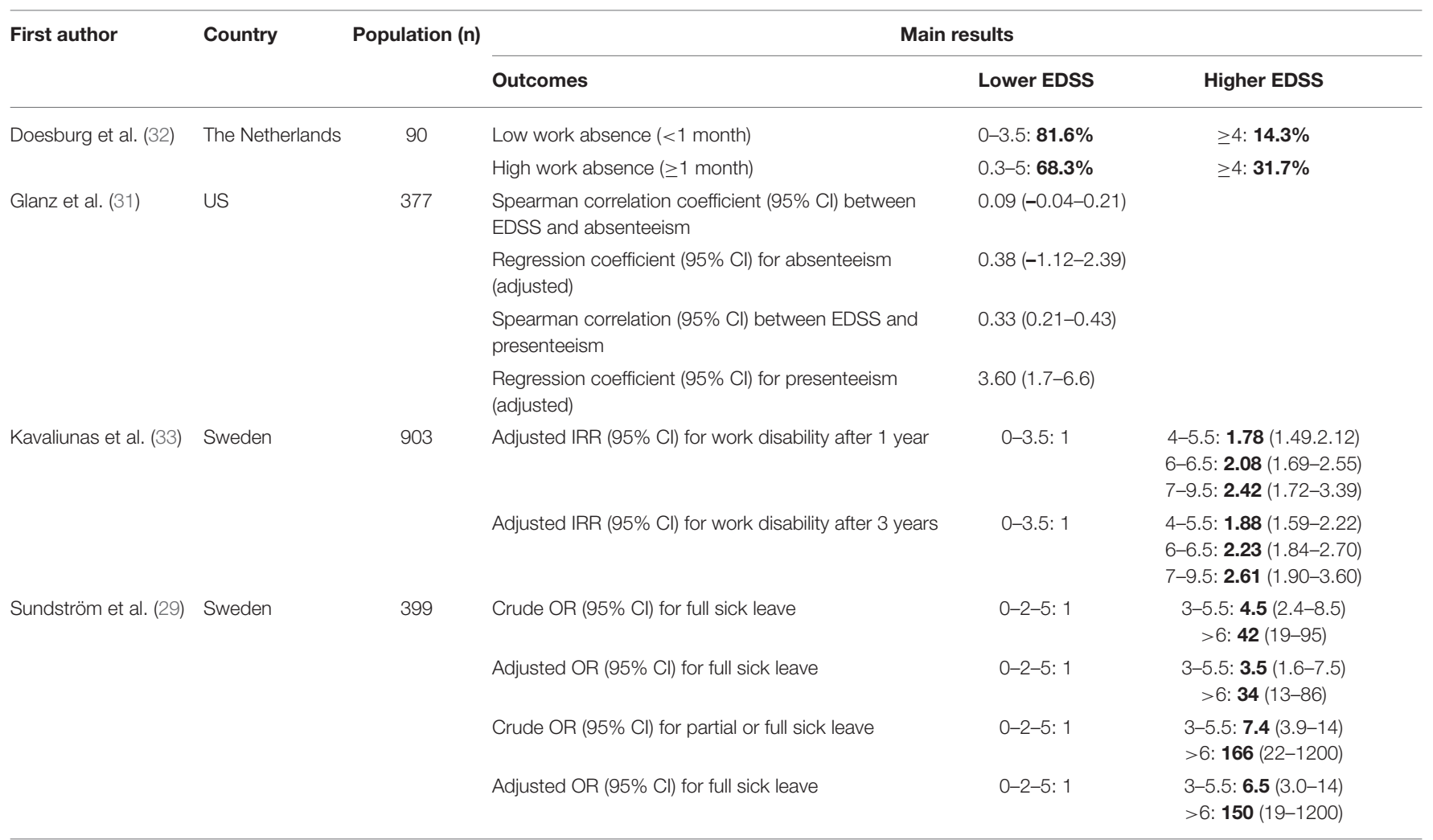

EDSS, Expanded Disability Status Scale; IRR, incidence rate ratio; OR, odds ratio. Bold values shows the estimate.

With regards to cognitive function, Kavaliunas et al. (33) reported that after 1 year of follow-up, those in the lowest SDMT quartile were estimated to have a $73 \%$ higher rate of work disability (operationalized as annual net days of sickness absence and/or disability pension) when compared with those in the highest SDMT quartile (IRR 1.73; 95\% CI, 1.42-2.10). At 3-year follow-up this estimate was similar (IRR $=1.68$; $95 \%$ CI, $1.40-$ 2.02). In addition, another Swedish study (30) pointed to a higher proportion not on full-time disability pension among those without cognitive impairment when compared with those with cognitive impairment ( $57 \%$ and $43 \%$, respectively). However, previously mentioned study in the United States (31) did not find significant correlations between absenteeism/presenteeism and cognitive function.

To sum up, the studies reported higher work disability in relation to higher physical disability and lower cognitive function.

\section{Relationship Outcomes}

There were two studies conducted in Sweden that reported relationship status, one cross-sectional (9) and one cohort study (Tables 8, 9) (33). None of the study investigated the relationship status as a socioeconomic outcome but reported only the respective proportions. With regards to physical disability, the proportion of the most common family compositionliving with a partner and with children-decreased with greater disability from $44.1 \%$ at EDSS $0-3.5$ to $17.3 \%$ at EDSS $7-9.5$; the most common family composition among the most disabled patients (EDSS 7-9.5) was to live alone (single and without children-52.7\%) (9). With regards to cognitive function, family composition did not differ significantly across SDMT quartiles $(p>0.05)(33)$.

\section{Education Level}

Information on the formal education level was available and extracted from the three included studies (Tables 8, 9) out of 19. Secondary education was the most common educational level among the persons with MS, overall (46.8\%) and in the different disability groups, while the percentage of persons with lower education increased from $8.2 \%$ to $18.6 \%$ and the percentage of persons with higher education decreased from $46.5 \%$ to $31.6 \%$ with greater disability (9).

As expected, when comparing persons with MS with the highest cognitive function in the fourth quartile (QIV) to those with the lowest cognitive function in the first quartile (QI), a smaller proportion had a lower educational level: 2.5 vs. $15.8 \%$, respectively (12); and 42.4 vs. $65.2 \%$, respectively, for lower or secondary education (33).

\section{DISCUSSION}

In this systematic review of the socioeconomic consequences of MS, we summarized findings of differences between persons with MS with regards to the physical disability and cognitive 
TABLE 7 | Studies that investigated work ability-related outcomes in patients with MS within different levels of cognitive function.

\begin{tabular}{|c|c|c|c|c|c|}
\hline First author & Country & Population & \multicolumn{3}{|c|}{ Main results } \\
\hline \multirow[t]{3}{*}{ Glanz et al. (31) } & US & 377 & $\begin{array}{l}\text { Pearson correlation coefficient ( } 95 \% \\
\text { Cl) between SDMT and absenteeism }\end{array}$ & $-0.08(-0.18--0.002)$ & \\
\hline & & & $\begin{array}{l}\text { Pearson correlation ( } 95 \% \mathrm{Cl} \text { ) between } \\
\text { SDMT and presenteeism }\end{array}$ & $0.08(-0.18-0.03)$ & \\
\hline & & & $\begin{array}{l}\text { Regression coefficient (95\% Cl) for } \\
\text { presenteeism (adjusted) }\end{array}$ & $0.06(-0.08-0.20)$ & \\
\hline \multirow[t]{3}{*}{ Kavaliunas et al. (33) } & Sweden & 903 & Work disability at baseline & $\begin{array}{l}\text { QIV: } 98.5 \\
\text { QIII: } 141.2\end{array}$ & $\begin{array}{l}\text { Qll: } 182.2 \\
\text { QI: } 229.9\end{array}$ \\
\hline & & & $\begin{array}{l}\text { Predicted marginal mean of work } \\
\text { disability (annual days) after } 1 \text { year }\end{array}$ & $\begin{array}{l}\text { QIV: } 143 \\
\text { QIII: } 191\end{array}$ & $\begin{array}{l}\text { Qll: } 203 \\
\text { Ql: } 247\end{array}$ \\
\hline & & & $\begin{array}{l}\text { Predicted marginal mean of work } \\
\text { disability (annual days) after } 3 \text { years }\end{array}$ & $\begin{array}{l}\text { QIV: } 154 \\
\text { QIII: } 188\end{array}$ & $\begin{array}{l}\text { Qll: } 206 \\
\text { QI: } 259\end{array}$ \\
\hline
\end{tabular}

IRR, Incidence rate ratio; Q, quartile; SDMT, Symbol Digit Modalities Test. Bold values shows the estimate.

TABLE 8 | Studies that investigated relationship outcomes and educational level in patients with MS within different levels of physical disability.

\begin{tabular}{|c|c|c|c|c|c|}
\hline \multirow[t]{2}{*}{ First author } & \multirow[t]{2}{*}{ Country } & \multirow[t]{2}{*}{ Population (n) } & \multicolumn{3}{|c|}{ Main results } \\
\hline & & & Outcomes & Lower EDSS & Higher EDSS \\
\hline \multirow{5}{*}{$\begin{array}{l}\text { Relationship } \\
\text { outcomes } \\
\text { Kavaliunas et al. (9) }\end{array}$} & Sweden & 7929 & Family composition: & & \\
\hline & & & Living with partner, no children & 0-3.5: 13.6\% & 4-5.5: 24.5\%; 6-6.5: 30.2\%; 7-9.5: 24.1\% \\
\hline & & & Living with partner and with children & 0-3.5: 44.1\% & 4-5.5: 33.9\%; 6-6.5: 26.8; 7-9.5: 17.3\% \\
\hline & & & Single, no children & 0-3.5: 33.6\% & 4-5.5: 32.5\%; 6-6.5: 35.5\%; 7-9.5: 52.7\% \\
\hline & & & Single, with children & $0-3.5: 8.8 \%$ & 4-5.5: 9.2\%; 6-6.5: 7.5\%; 7-9.5: 5.9\% \\
\hline \multirow{3}{*}{$\begin{array}{l}\text { Educational level } \\
\text { Kavaliunas et al. (9) }\end{array}$} & Sweden & 7929 & Lower & 0-3.5: $8.2 \%$ & $4-5.5: 14.5 \% ; 6-6.5: 17.6 \% ; 7-9.5: 18.6 \%$ \\
\hline & & & Secondary & 0-3.5: 45.3\% & 4-5.5: 50.7\%; 6-6.5: 49.3\%; 7-9.5: 49.8\% \\
\hline & & & Higher & 0-3.5: 46.5\% & 4-5.5: 34.8\%; 6-6.5: 33.1\%; 7-9.5: 31.6\% \\
\hline
\end{tabular}

function in terms of employment, income, work ability, family status, and education. All identified studies reported higher unemployment, higher early retirement, and higher odds for unemployment in relation to higher physical disability. In addition, cognitive function was found to be a predictor of employment (unemployment). The studies pointed out significant correlations between greater disability and lower earnings and higher income from benefits. Besides, one identified study showed the similar results with regard to the cognitive functions. The studies reported higher work disability in relation to higher physical disability and lower cognitive function.

Our results are in line with other studies that reported similar findings with regards to physical disability. For example, Findling et al. (22) reported median EDSS among fulltime working, part-time working, and among fulltime retired, which were 2.0, 3.0, and 5.0, respectively. Similarly, Koziarska et al. (26) reported a higher mean EDSS score among unemployed when compared with employed, 3.18 and 1.57, respectively. Corresponding results were also presented by Cadden et al. (34) (mean EDSS score among unemployed was 5.0 vs. 3.8 among employed), and Strober et al. (35) (4.62 and 3.13, respectively), as well as by Strober et al. (36) among women with MS (5.52 and 4.05, respectively). Lode et al. (37) reported mean EDSS score among those on disability pension-4.0 and among those not on disability pension-2.4. 
TABLE 9 | Studies that investigated relationship outcomes and educational level in patients with MS within different levels of cognitive function.

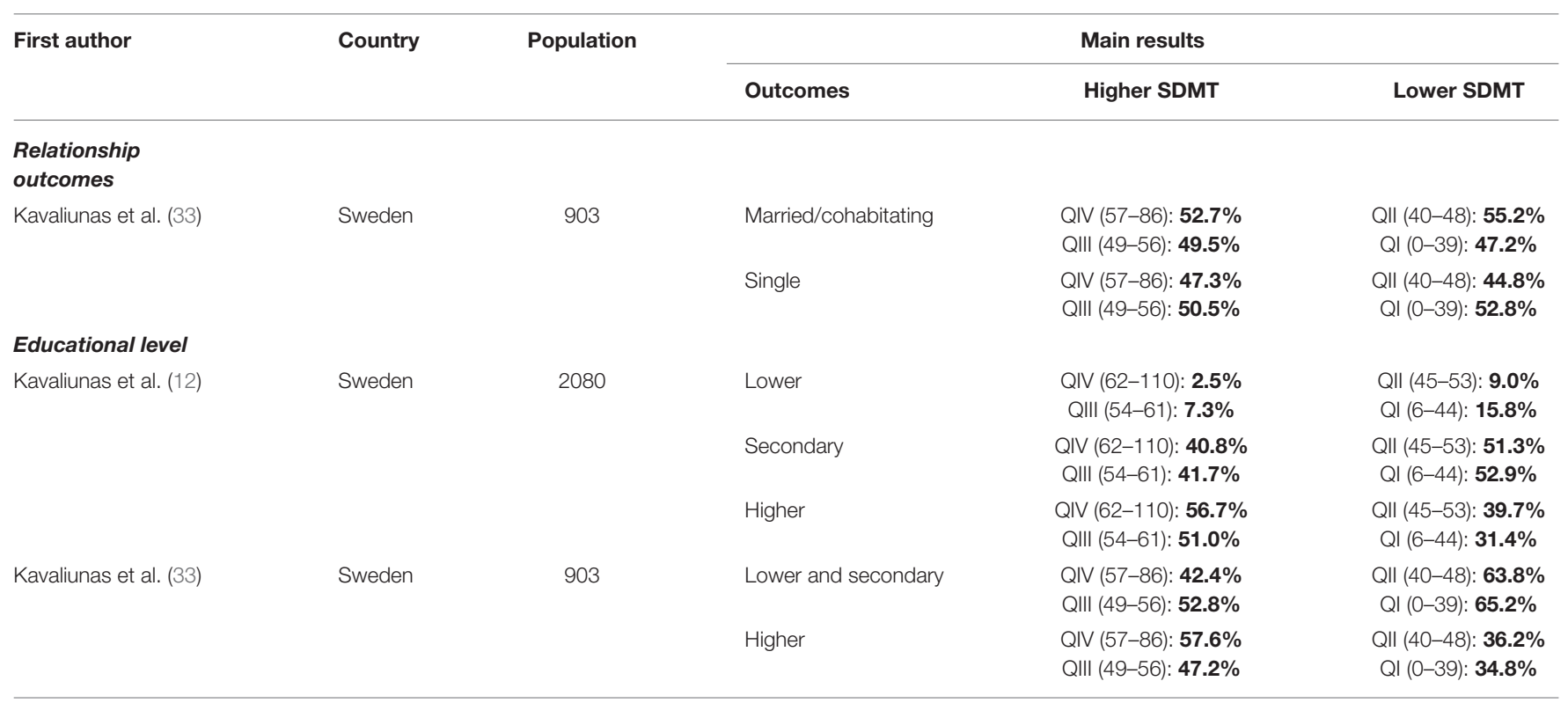

Q, quartile; SDMT, Symbol Digit Modalities Test. Bold values shows the estimate.

In addition, Campbell et al. (25) and Lau et al. (23) reported mean SDMT among employed and unemployed: 53.3 vs. 39.5 and 50.73 vs. 33.35 , respectively. Similar results, showing higher SDMT means among employed when compared with unemployed, were reported in several studies by Strober et al.: 43.69 vs. 34.28 , respectively (35), and 57.03 vs. 48.03 , respectively (38), or 53.59 vs. 45.52 , respectively (36). Additionally, Goverover et al. (39) found that the SDMT score among those employed and able to cook was 57.4, among those unemployed but able to cook-48.2 , among employed who did not cook-42.6, and among unemployed who did not cook-44.5. Lode et al. (37) reported mean SDMT score among those on disability pension-40.0 and among those not on disability pension-49.7. Furthermore, Moore et al. (40) using a multinomial logistic regression revealed the factors most strongly predictive of employment status were disability level, years of education, disease duration, and fatigue.

This is in line with a study that showed employment status to be associated with the Processing Speed Test (adaptation of SDMT) (41), whereas EDSS and SDMT were among the strongest predictors of employment status (35). In another study, higher level of disability and lower level of education at baseline predicted loss of employment at follow-up, however, not cognitive function (self-reported) (42).

Among the strengths of our study is that we assessed a wide spectrum of socioeconomic outcomes. As listed in Table 1, it is a heterogeneous field of investigation. Our mapping of these outcomes could help to define study outcomes when designing a study aiming at more comparable results and outcomes. Thus, we suggest reporting ratios (e.g., prevalence ratio for having income, $O R$ for sick leave, IRR for work disability) instead of proportions.

Due to this wide spectrum, it was not possible to assess the extracted information from the studies in a quantitative manner. In addition, the majority of the studies were cross-sectional in design. It is important to underscore that due to well-known limitations of cross-sectional designs, the correlations revealed in the studies may not necessarily be causative (e.g., high cognitive reserve (i.e., high employment status), may protect against cognitive decline, just as cognitive decline may contribute to unemployment in persons with MS). Given the chronic and progressive nature of MS, more studies with longitudinal approach are needed for more robust measures. Additionally, we were specifically looking into physical disability as assessed by EDSS and cognition as assessed by SDMT, however, there are many more various assessments and evaluations used in the clinical practice. Furthermore, the generalizability of the studies may be limited to countries with a similarly functioning labor market and welfare system. One additional aspect that can be explored further is comorbidity, as a study in Denmark found that both psychiatric and somatic comorbidity implied an increased risk of a low income 10 years after MS onset (43). A study in Sweden also concluded that psychiatric diagnoses and medications are common among patients with MS and adversely affect risk for disability pension (44).

By reviewing and summarizing the studies investigating the socioeconomic consequences, we illustrate how such outcomes can be used to study MS. The high correlation between EDSS and both earnings and benefits indicate that these could be used as proxies for disability in registry studies investigating factors of importance for MS progression (9). Cognitive function affects the financial situation of persons with MS negatively and independently of physical disability. This warrants cognitive testing as a routine measure at follow-ups for persons with MS. This is remarkable since SDMT by no means covers more than some aspects of cognitive impairment in MS. In addition, SDMT has outstanding qualities (superior reliability, sensitivity, greater patient acceptance, better psychometric validity and ease of administration compared with other processing speed tests, good correlation with MRI data, and with activities of daily living 
and employment) $(45,46)$. Within a brief battery of cognitive tests, the SDMT was found to be the test that best predicted future cognitive decline (47). SDMT was the only neuropsychological test which predicted impaired money management in patients with MS (48). Thus, a full cognitive assessment is likely to be more predictive of reduction of earnings. To allow persons with MS to adapt optimally to their situation, mapping of cognitive function should be considered mandatory in healthcare services (12). Cognitive function is, to a high extent, associated with future work disability in persons with MS, after adjusting for other factors. An interesting aspect that has also arisen from the results is the possible association of EDSS and SDMT-as patients with MS in the highest SDMT quartile had lower EDSS scores, i.e., a median of 2.0, whereas the patients in the lowest SDMT quartile had the median EDSS score of 4.0. Whether these measures are of different construct or reflect disease progression in a similar way, as well as how they change through the clinical course in relation to each other, might be well explored in future studies (33).

In conclusion, this systematic review summarizes the pronounced differences in various socioeconomic outcomes between persons with MS in regard to their physical disability and cognitive function. In addition, we identified lack of studies with longitudinal design in this field that can provide more robust estimates with covariate adjustments, such as the disease modifying treatments.

\section{DATA AVAILABILITY STATEMENT}

The original contributions presented in the study are included in the article/Supplementary Material, further inquiries can be directed to the corresponding author.

\section{REFERENCES}

1. Compston A, Coles A. Multiple sclerosis. Lancet. (2008) 372:150217. doi: 10.1016/S0140-6736(08)61620-7

2. Walton C, King R, Rechtman L, Kaye W, Leray E, Marrie RA, et al. Rising prevalence of multiple sclerosis worldwide: Insights from the Atlas of MS, third edition. Mult Scler J. (2020) 26:1816-21. doi: 10.1177/13524585209 70841

3. Manouchehrinia A, Beiki O, Hillert J. Clinical course of multiple sclerosis: a nationwide cohort study. Mult Scler J. (2017) 23:148895. doi: 10.1177/1352458516681197

4. Lunde HMB, Assmus J, Myhr K-M, Bø L, Grytten N. Survival and cause of death in multiple sclerosis: a 60-year longitudinal population study. J Neurol Neurosurg Psychiatry. (2017) 88:621-5. doi: 10.1136/jnnp-2016-315238

5. Dendrou CA, Fugger L, Friese MA. Immunopathology of multiple sclerosis. Nat Rev Immunol. (2015) 15:545-58. doi: 10.1038/nri3871

6. Kurtzke JF. Rating neurologic impairment in multiple sclerosis: an expanded disability status scale (EDSS). Neurology. (1983) 33:144452. doi: 10.1212/WNL.33.11.1444

7. Forbes A, While A, Mathes L. Informal carer activities, carer burden and health status in multiple sclerosis. Clin Rehabil. (2007) 21:56375. doi: $10.1177 / 0269215507075035$

8. García-Domínguez JM, Maurino J, Martínez-Ginés ML, Carmona O, Caminero AB, Medrano $\mathrm{N}$, et al. Economic burden of multiple sclerosis in a population with low physical disability. BMC Public Health. (2019) 19:609. doi: 10.1186/s12889-019-6907-x

\section{AUTHOR CONTRIBUTIONS}

$\mathrm{AK}$ and $\mathrm{JH}$ conceived and planned the study. AK, VD, and $\mathrm{JH}$ defined the search strategy. AK conducted the first screening of potentially relevant records based on titles and abstracts. $\mathrm{AK}$ and $\mathrm{VD}$ independently performed the final selection of included studies based on full text evaluation. AK, VD, and SB independently assessed the quality of the included studies. AK drafted the manuscript. VD, SB, and JH reviewed and edited the manuscript. All authors contributed to the article and approved the submitted version.

\section{FUNDING}

The study was financially supported by Biogen. Biogen courtesy reviewed the manuscript and provided feedback to the authors. The authors had full editorial control and provided approval to final content.

\section{ACKNOWLEDGMENTS}

For the help with the literature search, defining the search strategy, constructing the search string, and performing the search in the databases, we would like to thank Gun Brit Knutssön, Information Scientist, Karolinska Institutet University Library.

\section{SUPPLEMENTARY MATERIAL}

The Supplementary Material for this article can be found online at: https://www.frontiersin.org/articles/10.3389/fneur. 2021.737211/full\#supplementary-material

9. Kavaliunas A, Wiberg M, Tinghög P, Glaser A, Gyllensten H, Alexanderson $\mathrm{K}$, et al. Earnings and financial compensation from social security systems correlate strongly with disability for multiple sclerosis patients. PLoS ONE. (2015) 10:e0145435. doi: 10.1371/journal.pone.0145435

10. Sumowski JF, Benedict R, Enzinger C, Filippi M, Geurts JJ, Hamalainen P, et al. Cognition in multiple sclerosis: state of the field and priorities for the future. Neurology. (2018) 90:278-88. doi: 10.1212/WNL.0000000000004977

11. Toosy A, Ciccarelli O, Thompson A. Symptomatic treatment and management of multiple sclerosis. In: Handbook of Clinical Neurology. Elsevier (2014). p. 513-62.

12. Kavaliunas A, Danylaite Karrenbauer V, Gyllensten H, Manouchehrinia A, Glaser A, Olsson T, et al. Cognitive function is a major determinant of income among multiple sclerosis patients in Sweden acting independently from physical disability. Mult Scler Houndmills Basingstoke Engl. (2019) 25:104-12. doi: 10.1177/1352458517740212

13. Kavaliunas A, Karrenbauer VD, Hillert J. Socioeconomic consequences of multiple sclerosis-a systematic literature review. Acta Neurol Scand. (2021) 143:587-601. doi: 10.1111/ane.13411

14. Moher D, Liberati A, Tetzlaff J, Altman DG, Group TP. Preferred Reporting Items for Systematic Reviews and Meta-Analyses: the PRISMA statement. PLoS Med. (2009) 6:e1000097. doi: 10.1371/journal.pmed.1000097

15. Langdon DW. Cognition in multiple sclerosis. Curr Opin Neurol. (2011) 24:244-9. doi: 10.1097/WCO.0b013e328346a43b

16. von Elm E, Altman DG, Egger M, Pocock SJ, Gøtzsche PC, Vandenbroucke JP. The strengthening the reporting of observational studies in epidemiology (STROBE) statement: guidelines for 
reporting observational studies. Ann Intern Med. (2007) 147:5737. doi: 10.7326/0003-4819-147-8-200710160-00010

17. Kobelt G, Thompson A, Berg J, Gannedahl M, Eriksson J, Group the MS, et al. New insights into the burden and costs of multiple sclerosis in Europe. Mult Scler J. (2017) 23:1123-36. doi: 10.1177/13524585176 94432

18. Pearson JF, Alla S, Clarke G, Mason DF, Anderson T, Richardson A, et al. Multiple Sclerosis impact on employment and income in New Zealand. Acta Neurol Scand. (2017) 136:223-32. doi: 10.1111/ane. 12714

19. Battaglia M, Kobelt G, Ponzio M, Berg J, Capsa D, Dalén J. New insights into the burden and costs of multiple sclerosis in Europe: results for Italy. Mult Scler J. (2017) 23(2_suppl):104-16. doi: 10.1177/1352458517708176

20. Bøe Lunde HM, Telstad W, Grytten N, Kyte L, Aarseth J, Myhr KM, et al. Employment among patients with multiple sclerosis-a population study. PLoS ONE. (2014) 9:e103317. doi: 10.1371/journal.pone.0103317

21. Busche KD, Fisk JD, Murray TJ, Metz LM. Short term predictors of unemployment in multiple sclerosis patients. Can J Neurol Sci. (2003) 30:13742. doi: $10.1017 / \mathrm{S} 0317167100053403$

22. Findling $\mathrm{O}$, Baltisberger $\mathrm{M}$, Jung $\mathrm{S}$, Kamm CP, Mattle HP, Sellner J. Variables related to working capability among Swiss patients with multiple sclerosis-a cohort study. PLoS ONE. (2015) 10:e0121856. doi: 10.1371/journal.pone.0121856

23. Lau KK, Lau AY, Yu EL, Lau KM, Au A, Chan I, et al. Employment among multiple sclerosis patients in Hong Kong. Neurol Asia. (2016) 7:161-67.

24. MacLurg K, Reilly P, Hawkins S, Gray O, Evason E, Whittington D, et al. Primary care-based needs assessment of people with multiple sclerosis. $\mathrm{Br} \mathrm{J}$ Gen Pract. (2005) 55:378-83.

25. Campbell J, Rashid W, Cercignani M, Langdon D. Cognitive impairment among patients with multiple sclerosis: associations with employment and quality of life. Postgrad Med J. (2017) 93:143-7. doi: 10.1136/postgradmedj-2016-134071

26. Koziarska D, Król J, Nocoń D, Kubaszewski P, Rzepa T, Nowacki P. Prevalence and factors leading to unemployment in MS (multiple sclerosis) patients undergoing immunomodulatory treatment in Poland. PLoS ONE. (2018) 13:e0194117. doi: 10.1371/journal.pone.0194117

27. Morrow SA, Drake A, Zivadinov R, Munschauer F, Weinstock-Guttman B, PhD RHBB. Predicting loss of employment over three years in multiple sclerosis: clinically meaningful cognitive decline. Clin Neuropsychol. (2010) 24:1131-45. doi: 10.1080/13854046.2010.511272

28. Fraser RT, Clemmons D, Gibbons L, Koepnick D, Getter A, Johnson E. Predictors of vocational stability in multiple sclerosis. J Vocat Rehabil. (2009) 31:129-35. doi: 10.3233/JVR-2009-481

29. Sundström P, Nyström L, Svenningsson A, Forsgren L. Sick leave and professional assistance for multiple sclerosis individuals in Västerbotten County, northern Sweden. Mult Scler J. (2003) 9:515-20. doi: 10.1191/1352458503ms955oa

30. Chruzander C, Tinghög P, Ytterberg C, Holmqvist LW, Alexanderson K, Hillert J, et al. Longitudinal changes in sickness absence and disability pension, and associations between disability pension and disease-specific and contextual factors and functioning, in people with multiple sclerosis. J Neurol Sci. (2016) 367:319-25. doi: 10.1016/j.jns.2016.05.055

31. Glanz BI, Dégano IR, Rintell DJ, Chitnis T, Weiner HL, Healy BC. Work Productivity in relapsing multiple sclerosis: associations with disability, depression, fatigue, anxiety, cognition, and health-related quality of life. Value Health. (2012) 15:1029-35. doi: 10.1016/j.jval.2012.07.010

32. Doesburg D. High work absence around time of diagnosis of multiple sclerosis is associated with fatigue and relapse rate. Mult Scler Relat Disord. (2019) 31:32-7. doi: 10.1016/j.msard.2019.03.011

33. Kavaliunas A, Tinghög P, Friberg E, Olsson T, Alexanderson K, Hillert J, et al. Cognitive function predicts work disability among multiple sclerosis patients. Mult Scler J Exp Transl Clin. (2019) 5:1-8. doi: 10.1177/2055217318822134

34. Cadden M, Arnett P. Factors associated with employment status in individuals with multiple sclerosis. Int J MS Care. (2015) 17:28491. doi: 10.7224/1537-2073.2014-057

35. Strober LB, Christodoulou C, Benedict RH, Westervelt HJ, Melville P, Scherl WF, et al. Unemployment in multiple sclerosis: the contribution of personality and disease. Mult Scler J. (2012) 18:647-53. doi: 10.1177/1352458511426735
36. Strober LB, Arnett PA. Unemployment among women with multiple sclerosis: the role of coping and perceived stress and support in the workplace. Psychol Health Med. (2016) 21:496-504. doi: 10.1080/13548506.2015.1093645

37. Lode K, Bru E, Klevan G, Myhr KM, Nyland H, Larsen JP. Coping with multiple sclerosis: a 5-year follow-up study. Acta Neurol Scand. (2010) 122:336-42. doi: 10.1111/j.1600-0404.2009.01313.x

38. Strober L, Chiaravalloti N, Moore N, DeLuca J. Unemployment in multiple sclerosis (MS): utility of the MS functional composite and cognitive testing. Mult Scler J. (2014) 20:112-5. doi: 10.1177/1352458513488235

39. Goverover Y, Strober L, Chiaravalloti N, DeLuca J. Factors that moderate activity limitation and participation restriction in people with multiple sclerosis. Am J Occup Ther. (2015) 69:6902260020p1-9. doi: 10.5014/ajot.2015.014332

40. Moore P, Harding KE, Clarkson H, Pickersgill TP, Wardle M, Robertson NP. Demographic and clinical factors associated with changes in employment in multiple sclerosis. Mult Scler J. (2013) 19:1647-54. doi: 10.1177/1352458513481396

41. Macaron G, Baldassari LE, Nakamura K, Rao SM, McGinley MP, Moss $\mathrm{BP}$, et al. Cognitive processing speed in multiple sclerosis clinical practice: association with patient-reported outcomes, employment and magnetic resonance imaging metrics. Eur J Neurol. (2020) 27:123849. doi: 10.1111/ene.14239

42. Marck CH, Aitken Z, Simpson S, Weiland TJ, Kavanagh A, Jelinek GA. Predictors of change in employment status and associations with quality of life: a prospective international study of people with multiple sclerosis. J Occup Rehabil. (2020) 30:105-14. doi: 10.1007/s10926-019-09850-5

43. Thormann A, Sørensen PS, Koch-Henriksen N, Thygesen LC, Laursen B, Magyari M. Chronic comorbidity in multiple sclerosis is associated with lower incomes and dissolved intimate relationships. Eur J Neurol. (2017) 24:825-34. doi: 10.1111/ene.13297

44. Brenner P, Alexanderson K, Björkenstam C, Hillert J, Jokinen J, MittendorferRutz E, et al. Psychiatric diagnoses, medication and risk for disability pension in multiple sclerosis patients; a population-based register study. PLOS ONE. (2014) 9:e104165. doi: 10.1371/journal.pone.0104165

45. Benedict RH, DeLuca J, Phillips G, LaRocca N, Hudson LD, Rudick R. Validity of the symbol digit modalities test as a cognition performance outcome measure for multiple sclerosis. Mult Scler J. (2017) 23:72133. doi: $10.1177 / 1352458517690821$

46. Rao SM, Martin AL, Huelin R, Wissinger E, Khankhel Z, Kim E, et al. Correlations between MRI and information processing speed in MS: a metaanalysis. Mult Scler Int. (2014) 2014:975803. doi: 10.1155/2014/975803

47. Amato MP, Portaccio E, Goretti B, Zipoli V, Iudice A, Pina DD, et al. Relevance of cognitive deterioration in early relapsing-remitting MS: a 3-year follow-up study. Mult Scler J. (2010) 16:1474-82. doi: 10.1177/1352458510380089

48. Goverover Y, Haas S, DeLuca J. Money management activities in persons with multiple sclerosis. Arch Phys Med Rehabil. (2016) 97:19017. doi: 10.1016/j.apmr.2016.05.003

Conflict of Interest: AK is also employed by Takeda Pharma AB. VD has received financial support from Stockholm County Council; Biogen (recipient of grant and scholarship, PI for project sponsored by); Novartis (Scientific Advisory board member, recipient of scholarship and lecture honoraria); Merc (Scientific Advisory Board member, recipient of lecture honoraria). SB has received speaker's fee and had travel and conference expenses paid by Biogen. JH received honoraria for serving on advisory boards for Biogen and Novartis and speakers fees from Biogen, MerckSerono, BayerSchering, Teva, and SanofiGenzyme. He has served as P.I. for projects sponsored by, or received unrestricted research support from Biogen, SanofiGenzyme, MerckSerono, TEVA, Novartis, and BayerSchering. His MS research is funded by the Swedish Research Council and the Swedish Brain Foundation.

The authors declare that none of the funders were involved in the study design, collection, analysis, interpretation of data, the writing of this article, or the decision to submit it for publication.

Publisher's Note: All claims expressed in this article are solely those of the authors and do not necessarily represent those of their affiliated organizations, or those of the publisher, the editors and the reviewers. Any product that may be evaluated in 
this article, or claim that may be made by its manufacturer, is not guaranteed or endorsed by the publisher.

Copyright () 2022 Kavaliunas, Danylaite Karrenbauer, Binzer and Hillert. This is an open-access article distributed under the terms of the Creative Commons Attribution
License (CC BY). The use, distribution or reproduction in other forums is permitted, provided the original author(s) and the copyright owner(s) are credited and that the original publication in this journal is cited, in accordance with accepted academic practice. No use, distribution or reproduction is permitted which does not comply with these terms. 